\title{
"We are despised in the hospitals": Sex workers' experiences of accessing health care in four African countries
}

Fiona Scorgie $^{1 *}$, Daisy Nakato ${ }^{2}$, Eric Harper ${ }^{3}$, Marlise Richter $^{4}$, Sian Maseko ${ }^{5}$, Prince Nare ${ }^{6}$, Jenni Smit $^{1}$, Matthew Chersich ${ }^{7}$

$1^{*}$ Maternal, Adolescent and Child Health, Department of Obstetrics and Gynaecology, University of the Witwatersrand, South Africa, ${ }^{2}$ Women's Organization Network for Human Rights Advocacy (WONETHA), Kampala, ${ }^{3}$ African Sex Worker Alliance, Cape Town, South Africa, ${ }^{4}$ International Centre for Reproductive Health, Ghent University, Belgium; and African Centre for Migration \& Society, University of the Witwatersrand, South Africa, ${ }^{5}$ Sexual Rights Centre, Bulawayo, Zimbabwe, ${ }^{6}$ Nursing Sciences Department, University of Pretoria, Pretoria, ${ }^{7}$ Centre for Health Policy, School of Public Health, University of the Witwatersrand, South Africa; and International Centre for Reproductive Health, Ghent University, Belgium

\section{Email: fscorgie@match.org.za}

\begin{abstract}
Sex workers in east and southern Africa are exposed to multiple occupational health and safety risks. Detailed understanding of barriers to accessing care would optimise design of improved services for this population. In this study, trained sex workers conducted in-depth interviews $(n=55)$ and 12 focus group discussions with 106 female, 26 male and 4 transgender sex workers across 6 urban sites of Kenya, Zimbabwe, Uganda and South Africa. Data were analysed thematically, following an interpretive framework. Participants cited numerous unmet health needs, including diagnosis and treatment for sexually transmitted infections and insufficient access to condoms and lubricant. Denial of treatment for injuries following physical assault or rape, and general hostility from public-sector providers was common. Resources permitting, many sex workers attended private services, citing higher quality and respect for dignity and confidentiality. Sex workers in southern Africa accessed specialised sex worker clinics, reporting mostly positive experiences. Across sites, participants called for additional targeted services, but also sensitisation and training of public-sector providers. Criminalisation of sex workers and associated stigmatisation, particularly of transgender and male sex workers, hinder HIV-prevention efforts and render access to mainstream healthcare precarious. Alongside law reform, sex worker-led peer outreach work should be strengthened and calls by sex workers for additional targeted services heeded.
\end{abstract}

Keywords: sex work; prostitution; healthcare access; stigma; sub-Saharan Africa 


\section{Introduction}

Sex workers (SWs) are exposed to occupational health and safety risks that would be unacceptable in other professions. These risks are highest in Africa and include exposure to HIV and other sexually transmitted infections (STIs), alcohol and drug use, intense stress, urogenital problems, rape, and physical violence with musculoskeletal injuries and even death (Akers and Evans 2010; Rekart 2005; Ward and Day 2006). Contraceptive use is often inconsistent (Sutherland et al. 2011; Khan et al. 2009), and unwanted pregnancy and termination thereof is common. One study of female SWs in Kenya found that $86 \%$ had had at least one termination of pregnancy (Elmore-Meegan, Conroy, and Agala 2004). While many SWs are acutely aware of how to prevent STI transmission, they often have little power to enact this knowledge. Clients may force SWs to have sex without a condom or offer higher payments for unprotected sex (Adu-Oppong et al. 2007). Continent wide, SWs bear a disproportionate burden of HIV, with prevalence commonly 10-20-fold higher than the general population (Scorgie et al. 2012; Godin et al. 2008; Baral et al. 2012). Many SWs, however, consider the risk of violence to be a greater and more immediate threat than HIV, clearly demonstrating the everyday dangers and difficult conditions under which sex work commonly takes place (Nairne D 2000). Moreover, across Africa, with the exception of Senegal, sex work and/or related activities are criminalised. ${ }^{1}$

Until fairly recently, much of the research among SWs in Africa has dwelt on their potential to infect others - indeed, as 'vectors of infection' driving the HIV epidemic - rather than on SWs' own need for health services (Wolffers and van Beelen 2003) and their potential to serve as strategic safer-sex educators (UNAIDS 2011). Not enough is known about the day-to-day experiences of SWs as they attempt to access health services more broadly, and about how commonly such access is compromised or even denied outright, information that could be used to optimise the design of services for this population. Such services, with its consequent reduction in the burden of HIV and other STIs among SWs, should be prioritised within all HIV epidemic settings. Reducing these burdens would markedly improve the health of SWs, but also, evidence suggests (Steen, Chersich, and de Vlas 2012; WHO 2012), might interrupt transmission of these infections among their clients and the general population.

This paper reports a study in four countries of east and southern Africa that examined female, male and transgendered SWs' experiences of seeking public and private healthcare, barriers to accessing these services, and perspectives on how services might better address their needs. The study was commissioned by a continent-wide SW-led organisation, the African Sex Worker Alliance (ASWA), and its parent body, the

\footnotetext{
${ }^{1}$ In the study sites, sex work is an explicit criminal offence (Uganda and South Africa), or itself not a crime, but activities associated with it are (Kenya and Zimbabwe). Uganda's Penal Code Act, Section 139, states that a person engaging in prostitution commits an offence, liable to seven years imprisonment. In South Africa, sex work is a criminal offence under Section 20(1A)(a) of the 1957 Sexual Offences Act. Sections 153 and 154 of Kenya's Penal Code designate living off the earnings of sex work, and soliciting or importuning for 'immoral purposes' a criminal offence. Similarly, sections 81-87 of Zimbabwe's Criminal Law (Codification and Reform) Act makes soliciting, procuring and living off the earnings of sex work a crime.
} 
Sex Worker Education and Advocacy Taskforce (SWEAT), South Africa, as a contribution to the evidence base and to build a platform for coordinated advocacy in the study countries.

\section{Methods}

Interviewers collected narrative information directly from SWs through individual, in-depth interviews (IDI) and focus group discussions (FGD). This approach was chosen for its ability to capture rich and nuanced detail on the realities of SWs' lives (Arnott and Crago 2009). Interviews were conducted by peer educators affiliated to ASWA in the four study countries, who were already familiar with the working conditions of SWs by virtue of their own lived experience and advocacy work within these communities. Interviews were thus framed by a mutually respectful, non-judgemental context, and members of the SW community were capacitated and involved as active agents in research. Prior to data collection, peer educators (hereafter "interviewers") attended a three-day training workshop in South Africa, which covered qualitative research paradigms, basic interviewing skills and research ethics.

Data collection took place in six urban sites in four countries, namely: Mombasa, Kenya; Kampala, Uganda; Bulawayo, Zimbabwe; Hillbrow, Johannesburg and the towns of Musina and Thohoyandou in Limpopo Province, South Africa. Originally, sites in Mozambique and Nigeria were included in the study and interviewers from these countries attended research training. Due to logistical problems in Nigeria and delays in securing research approval from authorities in Mozambique, these sites did not contribute data to the study.

Study sites were selected as they are locations with existing ASWA operations and where the network is presently consolidating and extending its advocacy activities. Data collection was standardised across countries, although limited modifications to study tools were made to accommodate some countryspecific investigation. Data collection was coordinated by the principal investigator, based in South Africa (FS), and involved close supervision, albeit at a distance from field sites.

\section{Study population, sampling and recruitment}

During training, interviewers developed a brief synopsis of the SW community in their study area, based on outreach experience. This synopsis - providing detail on sex work settings (such as bar, brothel or street) and the proportion of the population who are migrants, for example - guided recruitment, which aimed to enrol samples that matched each profile. Snowball sampling was used, in which initial participants, matching the local synopsis, were identified through existing networks of the interviewers, and then asked to recommend others for potential recruitment.

SWs older than 18 years and who had at least one client in the past week (to capture current as opposed to former SWs) were eligible. The term "sex worker" was defined as involvement in sexual commerce, specified as "any agreement between two or more persons in which the objective is exclusively 
limited to the sexual act and ends with that and which involves preliminary negotiations for a price" (UNAIDS 2000).

\section{Data collection and analysis}

IDIs and FGDs were semi-structured, using interview guides containing mainly open-ended questions and some prompts. Questions covered the following themes: recent experiences of accessing healthcare, disclosure of SW status in healthcare settings, quality and coverage of HIV services, and strategies adopted to secure access to services and counter discrimination. Interviewers translated data collection tools into local languages, as required. Most interviews were audio-recorded, and then translated and transcribed by interviewers. Six participants declined recording, and for these, hand-written notes were taken.

Interviews were analysed thematically, following a grounded-theory approach (Strauss and Corbin 1998). This process (led by the PI) involved initial open coding of transcripts, then identification of key concepts that best summarised and explained the participant's experiences. Key concepts, forming an overarching conceptual framework, were then used to guide the remainder of the analysis and writing up of the data. This framework encompassed concepts such as: participants' greatest health needs; positive and negative experiences of accessing healthcare; stigma in health settings; and strategies for improving healthcare access for SWs. The conceptual framework was cross-checked by interviewers and three other members of the study team as the findings were being written up, to build a degree of consistency in overall interpretation.

\section{Ethical considerations}

Participants provided written informed consent, after explanation that participation was voluntary and that anonymity would be respected. Interviews were held in locations that maximised participant confidentiality and safety, such as the participant's own home, the interviewer's home or a private room in an NGO office. In each site, participants were referred to local counselling, health and legal organisations if required. Ethical approval for the study was granted by the Human Research Ethics Committee (Medical) of the University of the Witwatersrand, South Africa.

\section{Results}

Between December 2010 and January 2011, 106 female, 26 male and 4 transgender SWs were interviewed, 55 individually and 81 in FGDs. Twelve FGDs were held in total, each with between five and eight participants. Participants per site ranged from 23 in Mombasa to 30 each in Kampala and Limpopo.

\section{Profile of participants}

Across sites, the mean age of women ranged between 26 years in Limpopo and 36 in Bulawayo. Nearly half the women in Limpopo province were 25 years or younger, while women in other sites were mostly aged 2535 years. The mean age of men was 26 years, ranging from 20 to 36 years. The transgender participants, 
three from Mombasa and one from Hillbrow, were aged 25 to 34. In the South African sites, a large proportion of women had completed secondary school ( $93 \%$ in Hillbrow and $83 \%$ in Limpopo). By contrast, most of the Ugandan (63\%) and Zimbabwean (48\%) women had only attended primary school. Three of the four transgender participants had none or primary education only, while around $80 \%$ of the men had secondary or higher education. Overall, only a handful of participants had tertiary-level qualifications. Most women had children, with almost a quarter having three or more. By contrast, only one transgender participant had a child, and $81 \%$ of men had none.

None of the women in Mombasa, Kampala and Bulawayo were foreign migrants, although most had been born outside of the cities in which they now worked. Conversely, around $60 \%$ of participants in both Hillbrow and Limpopo were cross-border migrants - almost without exception, from Zimbabwe. Among the males, $25 \%$ were foreign migrants, with a further two thirds born outside their city. The same proportion of transgender were foreign born, while the remainder were born in the cities they now worked in.

Duration of sex work varied considerably, with some women reporting as many as 20 years in the industry. Male participants had been SWs for a mean 6 years, transgender participants for 13, while average duration among women varied from 11.3 years in Mombasa to only 3.5 years in Limpopo. Transgender SWs reported 6 to 26 clients in the past week, men a median 6 in the past week, and for women this figure ranged from 20 in Mombasa and Kampala to around 5 in Limpopo and Bulawayo. About $60 \%$ of the women said they had an income source aside from sex work, although usually erratic. No transgender participants had other forms of employment, but one quarter of men did.

\section{Sex workers' most prominent health needs}

SWs listed a wide range of health needs, a number of which could be considered occupational health problems arising from the particular contexts of sex work itself. Foremost amongst these is the frequent exposure to STIs, and the consequent need for proper STI diagnosis, treatment and follow-up. Among east African participants, contracting STIs was largely perceived as "inevitable"; as one put it, "there's no way we can avoid STIs" [Female, Kampala]. Some women reported frequently experiencing "lower abdominal pain" - potentially a sign of untreated STIs or other reproductive health problems. Discomfort and even injury during sexual intercourse was also common. Sibongile ${ }^{2}$, a 21 -year old woman in Limpopo narrated the following experience:

"I found a client, and he was bigger than me, as you can see I'm thin. He slept with me in bad way. Then when we finish, I try to stand up I feel pain inside me. And by that time I could not stand up. He took me to a hospital. The nurse told me that I have injured inside my womb then they told me that they are going to take out my womb because they can't operate it, now I'm living without a womb."

\footnotetext{
${ }^{2}$ All participant names in this article are pseudonyms.
} 
Many women expressed an unmet need for pap smears and female condoms. Unplanned pregnancies - often terminated in extremely unsafe conditions - were reportedly common. Aside from South Africa, termination of pregnancy is either illegal or only permissible under limited circumstances, placing safe abortion beyond women's reach in these countries. Eve from Mombasa (aged 26 years) explained:

"Whenever I forget to use a condom I get pregnant, but I don't like hospitals. I buy medicines from pharmacies and terminate my pregnancy. I use alcohol to remove pain."

The profound vulnerability to HIV infection faced by SWs across Africa emerged as a strong theme. Much of this is linked to the violence that accompanies sex work and the twin contexts of patriarchy and criminalisation of SW that together undermine their ability to protect themselves.

“One time I went with a client - I don't know whether he was a police man or not because he had a pistol. He forced me and removed the condom and had unprotected sex with me. After some time, when I went for HIV testing I was positive, yet earlier I had tested negative before having unprotected sex with him.” [Jackie, 26 years, Kampala]

The need for medical attention for physical injuries following beatings and rape was described by virtually all participants, whether female, male or transgender. As detailed below, however, such treatment was often denied when health providers realised or knew they were SWs. Participants hinted at long-term traumatisation resulting from high levels of abuse and public humiliation, which manifested most frequently as depression, anxiety and self-loathing.

“...whenever somebody degrades you, you always feel ashamed and become sad” [Nomusa, 38 years, Hillbrow (female SW)]

"It's a risk to do this job. A lot of the SWs are dying, and no one is taking care about these problems. You put your life in a small bottle, you can’t breathe." [John, 21 years, Hillbrow]

\section{Experiences accessing healthcare}

\section{Healthcare-worker hostility and denial of treatment}

Participants cited broad challenges with accessing public-sector facilities that are presumably common to all patients attending these facilities. These included, primarily, long waiting times, high user fees, medicine shortages and inadequate transport to hospitals. But SWs experienced several additional barriers to receiving decent care. Providers were described as "abusive" and "hostile", at times explicitly withholding treatment, referring SWs unnecessarily, or explicitly blaming SWs for their illnesses.

"When I fell sick and went to a health centre and they realised that I was a SW, they did not treat me like a human being. When the health worker came to attend to me she said that I should go to the other health worker and when I reached the other health worker, I was told that he had no time for me. So I left without getting treatment." [Anna, 19 years, Mombasa] 
"We are despised in the hospitals. They [providers] say, 'We don't have time for prostitutes' and they also say that if one prostitute dies then the number reduces." [Belinda, 27 years, Kampala]

Discriminatory treatment was applied even at times to family members of SWs who accompanied them to health facilities. One participant recounted being pushed to the end of the queue when bringing her child for treatment and was attended to only after all other patients had been seen.

Accessing STI services was described as a major challenge across sites. Accounts emerged of having to bribe health workers for treatment in Uganda and Zimbabwe, where SWs had to pay extra for STI treatment. Providers in these countries were also said to apply treatment guidelines that are only relevant for people within monogamous, long-term relationships, thus compromising SWs' STI treatment. In Zimbabwe, two respondents were refused treatment because they could not bring their partners along. Another shared the following experience:

"When you go to the hospital the health workers say, 'We will not treat you unless you come with your husband'. We don't have husbands, so we go to drug shops and buy some drugs to relieve us from the pain." [Mirembe, 25 years, Kampala (female SW)]

Not all experiences of public-sector facilities were abusive, however. Although rare, some described their relationship with clinic nurses as "good", while others recounted positive experiences in public hospitals:

"I had a cyst...I went to the hospital and they treated me very nice" [Rita, 28 years, Bulawayo].

A female in Kampala who sought treatment for an STI at a government hospital reported having "a good reception", and being treated "like a general patient", despite being known as a SW by the health workers there.

\section{Violations of privacy}

A common finding was that when participants attend public facilities, health providers ask what work they do and - if sex work is disclosed - this information is revealed to other providers and even to accompanying relatives. SWs are also commonly interrogated unnecessarily, asked inappropriate questions or encouraged to exit the sex industry:

"One time I went to the hospital where they knew me and the health worker started saying, 'Imagine, a beautiful girl like you selling yourself. Why can't you get a man and get married?' Imagine, I was sick but that is what he had to say. I answered him, 'Do you think I'm very happy doing this kind of work? I have many problems and that's why I'm doing this work...” [Belinda, 27 years, Kampala]

Male SWs in particular are often seen as a curiosity by health workers:

"One time I had a problem and went to a clinic and I explained to the doctor and the doctor was like,

'Let me come back' and after five minutes I saw all the nurses coming and peeping in the room 
looking at me and going back. So when the doctor came back I asked him, 'Have you said anything to these people? So I don't have a right to confidentiality between me and you?"' [Jerry, 27 years, Kampala]

This form of stigmatisation and breach of confidentiality is even more acutely experienced by transgender SWs. Tracey, a 25-year old transgender participant in Hillbrow, recounted the following experience after being gang-raped by clients:

"I go to report to the police, they told me to go to the hospital and 1 was still wearing my jeans, wig and with my breast. When the doctor examined me and find out that 1 am a she-male, he called other doctors and nurses. They left their work to come and see that a man got raped. It was like a mockery... The doctor told me I was not raped but I was sodomised because I am a man. The way 1 was dressing they said 'what kind of a woman [are you]?' I just walked from the hospital without being treated. It was not fair because 1 was raped the whole night."

Related to these scenarios are instances of overt homophobia against male SWs, who incur a 'double stigma'. Some participants even regarded homophobia as worse than the stigma and discrimination they faced as SWs. Lee, a 28-year old, Hillbrow-based male SW, believed that religious bigotry underlay the attitudes of the female nurses who showed reluctance to treat him:

“So just maybe being gay around their Christianity, they don't believe in being gay. And they talked behind my back, [saying] 'We are sick and tired of these gay people coming here with their piles and anal problems."

Not surprisingly, most of the SWs we interviewed simply chose not disclose their work to health professionals. Even when the reception from health workers was initially positive, participants feared that revealing their SW status would change this response.

"I cannot go and tell a health worker that I have a genital problem when she doesn't know about my work. I expect to be abused and I have fear." [Anna, 19 years, Kampala]

"l am shy to say that 1 am SW because if you tell them, they don't treat us. So we lie....it's better to say 1 work as a housemaid." [Busi, 36 years, Musina (female SW)]

A similar strategy was described by Vuyo in Bulawayo (21 years), who sometimes misrepresented his health problems in order to sidestep difficult questions:

"When we go to the clinic we will be scared to tell the nurse because they will start asking you, 'Where did you get it? How did you get it?' So it will be really painful for me to say I got it like this or I was doing this. So I will end up lying which will make me not to get the right medication."

Indeed, non-disclosure of SW status was recognised by many participants as undermining diagnostic accuracy and treatment effectiveness, and some acknowledged that non-disclosure was ultimately not a 
solution. Eli, a male SW from Hillbrow aged 35, reflected: "It's better they [health providers] know what problems SWs are facing" and called instead for dedicated facilities providing services for SWs alone.

\section{Accessing HIV services and commodities}

About one third of participants claimed to know their HIV status, while others reported being unaware of where to go for a test, or said they could not afford transport costs or user-fees. Underlying these responses, although not explicitly voiced, was perhaps a form of "self-stigma" that results from the internalisation of broader social discrimination against people living with HIV, and which appears to be magnified for SWs with HIV. A strong theme in the interviews, regardless of study site, was the impact of overt discrimination and consequent social isolation on SWs' willingness to get tested for HIV.

"They fear that if tested positive they will be mistreated. Unless someone is strong they can go for testing, but not all of us have strong hearts.” [Eve, 26 years, Mombasa]

Mirembe, a female SW based in Kampala (25 years), described the extent to which this stigma even pervades the SW community, preventing disclosure, delaying treatment and scuppering opportunities for support among SWs themselves:

"When SWs get to know that you are HIV positive, when they see you with a client they tell the client not to take you, that you are sick and you are on treatment. You may go with your friend for testing. Now when your friend gets to know that you are HIV positive you will fear to go to the hospital for treatment till you are ill because you wouldn't want your friend to notice you going for treatment."

Only three participants mentioned having been forced to have an HIV test against their will or being tested surreptitiously without consent (in Hillbrow, Kampala and Limpopo). Also, only few recalled having sought a test, but being denied this service altogether.

"When the [doctor] who tests came, he was rude. I explained to him and told him that I was a SW and I wanted to get tested for HIV. And he told me, 'we don't have time here for SWs'. He told me to come back tomorrow and he went. I kept on going there, but was not tested." [Phyllis, 27 years, Kampala]

Participants in all sites except Hillbrow reported difficulties in accessing male condoms, particularly when working in locations on the outskirts of cities or in rural areas. In Bulawayo and Kampala, condoms were sourced free of charge from local and international NGOs, HIV clinics and hospitals, or purchased from retailers or vendors outside bars. SWs living in rural areas outside Kampala reported frequent difficulties in accessing condoms at all. At times they would resort to expired or used condoms, or stop work for a period: 
“...in Migyera we searched for condoms and failed to get them and we gave the job a break till we were [helped] by someone who came to town and brought for us some condoms... it took us four days without condoms and not working." [Anna, 19 years, Kampala]

In Thohoyandou, Limpopo, participants bought condoms from spaza shops [small independent trading stores] and petrol stations, and obtained them free from local NGOs, although these sources were considered largely unreliable. In most instances, however, condom supply was curtailed by the very institutions that one would expect to support distribution of safer-sex commodities. Health workers at public facilities were described as restricting the number of condoms per client: "they give you one packet and say, 'share that packet'." [Patience, 25 years, Musina]. One clinic in Musina reportedly sold government-issue condoms to patients, rather than distributing them free of charge. At this clinic, condom distribution had even become a bargaining tool for some male health workers to secure sex:

"There is one male worker [at the clinic] who bring condoms for me and ask me to have sex with him because he bring me something so I must have sex with him... [it means] it's not for free, you have to exchange it with something." [Zinhle, 26 years, Musina (female SW)]

Evidence from one of the local NGOs in Thohoyandou, which has been monitoring condom supply in the town, suggests that it is common practice for police to seize condoms from SWs, burn informal condom distribution sites established by SWs, and arrest anyone found with condoms at night.

One consequence of these difficulties in accessing condoms was that SWs' desire to practice safer sex cut into their earnings:

"Now we are forcing a client to buy condoms and deduct his ten rand [+/-£0.72] from the money he is supposed to pay you." [Tendai, 30 years, Musina (female SW)]

Across all sites, female condoms were almost impossible to source, although highly desired by female SWs. Few reported having direct experience of lubricant use, and in many cases, had never seen lubricant or understood its purpose. In Uganda, however, both male and female SWs said they had been able to access lubricant from a local NGO in the past, and made a strong plea for improved and regular access.

"My first time I saw it from WONETHA, but the way it helped us we really liked it and we request for support that we get more lubricant because it made us happy.” [Amy, 28 years, Kampala]

When asked why lubricant access was so important, their responses revealed what a difference it would make to SWs - from a health and wellbeing point of view - if this commodity were readily available.

"No matter how big the man is he can still enter you... even if you go with ten clients in one night even twenty everything moves on smoothly...this lubricant makes you smooth and soft. When a client is entering you...this also prevents the condom from breaking." [Florence, 24 years, Kampala] 
“At times if you don't have lubricant you end up with some cuts because there are different [sized] penises, so when you use lubricant it goes easy.” [Bongani, 24 years, , Hillbrow (Male SW)]

Male participants in Hillbrow strongly concurred, pointing out that lubricant had to be purchased from pharmacies and was expensive. As a consequence, alternative oil-based substances - such as "lotion and Vaseline" - were used instead, which could undermine the integrity of latex condoms.

\section{Alternatives to the public sector}

We were particularly interested to know more about SWs' encounters with targeted health services. Only participants in the southern African sites mentioned such experiences. Virtually all those interviewed in Hillbrow had used Esselen Street Clinic for HIV testing or treatment, contraceptives and other services. This clinic - run by a large, well-established research institution in the area - is specifically for SWs. On the whole, health workers here were said to have a "good attitude".

"They treat you nicely. They do understand who they are work with and dealing with...everything it's okay at Esselen.” [Lebohang, 26 years, Hillbrow (female SW)]

SWs in Musina spoke of receiving services from a local clinic for refugees and cross-border migrants established by an international NGO, and which treated clients with dignity. Similar sentiments were expressed by SWs in Bulawayo describing a new targeted SW clinic run by a local NGO with international funding:

"Lately, things have changed because of the new clinic that has opened for SWs. They are friendly and they treat us in a respectful manner." [Patience, 25 years, Bulawayo]

"It's generally safer for us to go to the SWs' clinic than to the public clinic where you will get people judging you or laughing at you because you are a SW or because you have an STI." [Mbali, 36 years, Bulawayo (female SW)]

But if the money could be found, SWs accessed private services instead.

"I really like private hospitals because of their good service and if you ask me to go to Government hospital, it's like you are asking me to burn my hand.” [Aisha, 28 years, Mombasa]

Almost unanimously, participants described private health services as being of higher quality than the public sector. Private facilities were widely regarded as "friendly" places where SWs would be treated with dignity and their confidentiality respected. After being shouted at by a doctor in a public-sector hospital in Mombasa, when Aisha had a suspected STI, she sought treatment instead at a private facility:

"I was well counselled and they treated my infections very well until I was healed. I like that doctor, even he advised me to do a HIV test but I declined by telling him I am not ready. And he replied to 
me, 'It's OK, when you are ready come for the test.' I was very happy for myself with the way that doctor treated me."

Private doctors were also favoured because they were known to not inquire too closely about the work done by SWs, or deny them care:

"...last time I go to the clinic bleeding too much, they didn't treat me and told me, "You are a SW, you want sex too much, we can't treat you." So I go to the private clinic; they treat me nice." [Zinhle, 26 years, Musina]

At least one male and one transgender participant described rare experiences of being cared for by private health workers in an atmosphere of acceptance and non-discrimination, in stark contrast to the homophobia commonly encountered in public-sector facilities.

"I had an STI last month and I went to a private clinic. They treated me well and even I had told them that I am gay and a SW, they were still friendly. I even now know my HIV status because they encouraged me to get tested." [Fred, 38 years, Bulawayo]

“There was good hospitality and the service provider didn't say anything bad about me. He answered all my questions according to my need." [Kim, 32 years, Mombasa (transgender SW)]

Two final alternatives to public healthcare services included the options of self-treatment with home remedies or over-the-counter medication, and seeking out the services of a traditional healer or herbalist. The latter option was mentioned only by participants in Bulawayo and Hillbrow, and appeared to be a favoured treatment for STIs.

"It's tough, especially when you suffer from an STI, they treat you like you just got what you deserve, and we end up using some traditional herbs because the traditional healers don't ask too many questions." [Thuli, 35 years, Bulawayo (female SW)]

\section{The future: SWs identify strategies for change}

We asked participants to articulate how they thought services for SWs should ideally be structured and how existing barriers to healthcare could be addressed. Most of their suggestions were direct responses to the shortcomings and challenges identified in the public sector and described above. Firstly, participants across sites called for training of health providers to sensitise them to the needs of the SW community. Secondly, the idea of a 'supporter' or 'advocate' in health settings was put forward: a person to represent SWs in the face of open hostility or a lack of an empathetic response from providers.

"...we want people to stand for us because they [health providers] don't understand us when we go to the clinic" [Zinhle, 26 years, Musina]

As a third suggestion, there were many calls for 'sex-worker specific' facilities and services: 
“...we SWs should be given our own hospital where we can disclose our status and what we are suffering from...a hospital where we can go and disclose and open up to the health workers." [Susan, 33 years, Kampala]

Then, in Limpopo, the need for better access to information about health was strongly emphasised, perhaps highlighting the extent to which SWs in this area are marginalised and thus not reached by mainstream health education.

"Bring an expert of health who can teach us about healthy issues so that we feel free to ask some of the things we want to know." [Tendai, 30 years, Musina]

Finally, a strong theme was the need for SWs to work together as a unified community, lobbying with a single voice for their rights to health care to be respected. This collective action was considered a challenge, however, given intense competition for clients in some environments. In Limpopo, participants in a FGD described "jealousy" between SWs that often undermines attempts at co-operation, even at times extending to physical violence among SWs.

Many participants noted the influence of the broader context of criminalisation and social exclusion on their health and experiences of interacting with the healthcare system. Elise, a 29 year old SW in Kampala, shared with us her conviction that this context impacted directly on SWs' ability to protect themselves from HIV:

“...the government says that this work is not recognised and they don't give us condoms because they think that when they give us condoms we will promote sex work. So this suppresses me because even if I'm a SW I'm entitled to protect myself."

Aside from curtailing their access to health services, the illegality of sex work was also understood to lend legitimacy to ongoing abuse and humiliation of SWs. Several strong calls for the removal of criminal laws were made:

"If sex work is allowed, you would be working freely just like other jobs and you cannot be stigmatized by the community and police.” [Kedi, 26 years, Hillbrow (female SW)]

In a similar vein, and speaking to the broader social context of anti-SW discrimination, Elise from Kampala neatly captured how increased social inclusion might improve overall health and wellbeing for SWs and ultimately change their lives:

"But the best thing would be working together, because we are from one country, same blood. Because when you discriminate against someone, this brings a lot of pain in someone's heart and this can lead to death. Everyone needs to be loved." 


\section{Discussion}

The study found that discrimination against SWs was widespread, particularly in public-sector facilities, where it was common for SWs (once their occupational status became known) to be ignored, denied treatment, insulted and - particularly for male and transgender SWs - treated as objects of curiosity by health providers. SWs' access to state-provided health services is clearly hindered by prejudicial provider attitudes which reflect the stigma attached to sex work in these societies more broadly. This echoes previous findings (Stadler and Delany 2006; UNAIDS and Kenya National AIDS Control Council 2009), especially notable in one study in Zimbabwe, where nurses publicly derided SWs and attended to them only after seeing to all other clients (Pswarayi 2010). Experiences of SWs in the four countries were broadly similar, with relatively few distinguishing features across sites. There were important exceptions to this general experience of discrimination, however. Although few and far between, some participants reported receipt of respectful and satisfactory treatment by health workers, mainly in the private, not-for-profit or NGO sectors. These positive experiences are important to document as they illustrate that delivery of high-quality healthcare to SWs is within reach, even in the public sector.

Where they exist, dedicated SW clinics appear to be most successful in the settings studied. These services are offered in many places on the continent (Stadler and Delany 2006; Lafort et al. 2010; Luchters et al. 2008), but generally have low overall coverage and are of uncertain sustainability. These are mostly run by NGOs or research groups, and are largely disconnected from broader government efforts to address the HIV epidemic. Strong calls by SWs in our study for targeted, SW-specific facilities should be heeded, but with caution. In theory, such dedicated facilities could become stigmatised in themselves if attitudes in the broader society remain unchanged, although no evidence for this emerged in our findings, where many participants actually strongly endorsed such facilities.

In the long term, a mix of both models may be the answer: sex-work specific clinics in areas of high SW concentration, linked to programmes for training and sensitisation of providers in mainstream facilities. The literature on integration of HIV and sexual reproductive health services for the general population potentially provides useful models that could be adapted to this context; these models have shown evidence of increased uptake of services following integration, reduction of HIV-related stigma, and improved coverage of services for underserved and at-risk populations (Church and Mayhew 2009). Some degree of adaptation will be required to mainstream services if they are to meet the needs of the SW community. For example, existing approaches to STI diagnosis and treatment for SWs, which assume monogamous, longterm sexual partnerships to be the norm, are clearly inadequate.

Training is required for health workers to sensitise them to SWs' specific needs and the inappropriateness of interrogating SWs about what they do or of encouraging 'rehabilitation'. Wherever possible, SWs themselves should lead these initiatives. Performances by SW-led drama sensitivity groups in clinics in Cape Town, South Africa, for example, have been used to show providers how SWs are denied STI treatment, to apparently favourable responses from clinic staff. A more systemic approach involving 
engagement with higher levels of authority is also required, through dialogue with relevant Ministries of Health. Encouragingly, SWs have been included in recent panels responsible for devising SW guidelines for WHO and South Africa.

Irregularity of condom supplies was a disturbing finding emerging in this study. Concerted efforts are needed to ensure that sex work settings have reliable condom stocks, especially entertainment establishments such as bars, clubs and hotels. A clearly neglected issue is the distribution of lubricants and sufficient female condoms. Once available, demand for the latter may rise rapidly, as found in a recent female condom promotion project in the Thohoyandou site, implying that supply systems need to anticipate sharp increases in demand.

SW-led outreach is a particularly pertinent strategy to improve condom access, and to win the support of owners and staff members at these venues (Lafort et al. 2010; Luchters et al. 2008). Peer educators also could play a key role in reaching 'hidden' SW populations - particularly migrant and injecting drug-users. Moreover, peers should specifically seek out SWs who have lost trust in the health system, following hostile or abusive interactions with providers. A clear area for intervention is addressing SWs' fears of and reluctance to access HIV testing. Within a rights-based approach, initiatives to increase uptake of these services should pay special attention to ensuring that SWs receive sensitive counselling, emotional support, and high-quality treatment and care for those testing positive. SWs in southern Africa have engaged in strategies to diminish violence and challenge the view held by health workers and others that such violence is acceptable (Arnott and Crago 2009). Further research is needed on the success of these strategies in the long run, how to enhance their impact and how untapped resources within SW communities could be accessed to build collective solidarity among individual SWs. Additional research could focus on developing and testing interventions to alter health workers' attitudes towards SWs.

\section{Limitations}

The participation of fewer countries than initially planned limits the ability to generalise these findings. Also, 'snowball' sampling tends to recruit SWs that are more visible, cooperative, and interested in participating in research, rather than capturing a truly representative sample (Shaver 2005). Although efforts were made to select a heterogeneous sample that reflected the diversity of the SW population in each site, we cannot determine whether this was achieved.

Most interviewers had little or no previous research experience, since their background was essentially that of peer education and outreach work, and supervising data collection at a distance posed several additional challenges. By placing full responsibility for data collection and transcription in their hands, however, they were able to learn valuable research skills and broaden their understanding of the experiences of SWs in their area. They built new relations with SWs who had not previously been involved in ASWA activities and thus opened-up future capacity-building possibilities. Finally, using the available data, we drew distinctions between the experiences of female, male and transgender participants, as far as possible. 
Disaggregating SWs' experiences by gender was not, however, a primary objective of the study, but future research could address this by recruiting sufficient participants from each gender and ensuring that interviewers and study team members apply a pre-specified gender classification in their analyses.

\section{Conclusions}

SWs in the study countries, and indeed virtually continent-wide, are marginalised and face human rights violations and discrimination, all of which hamper their access to health services. Criminalisation of sex work facilitates such violations, drives sex work underground, creates socially-excluded communities and impedes initiatives to prevent transmission of HIV and other STIs (WHO 2005; Ahmad 2001; UNAIDS 2009). Decriminalisation would make sex work safer and create an environment more conducive to negotiating safer business and sexual transactions. This occurred in New Zealand where sex work was decriminalised in 2003 (Open Society Foundations 2012; Prostitution Law Reform Committee 2008), and is the legal position recommended by UNAIDS and other international bodies (Secretariat: The Global Commission on HIV and the Law 2012).

Alarmingly, SWs we spoke to in Kampala mentioned the impending introduction of laws that specifically criminalise SWs found to be HIV positive. Initially, proposed amendments to the Ugandan HIV and AIDS Prevention and Control Bill would have criminalised the transmission of HIV and included provisions for mandatory HIV-testing of SWs and others (Human Rights Watch 2010). Though ultimately not all these amendments were passed, the proposal signalled that disturbing attitudes towards SWs are entrenched in the public sphere and remain in active circulation. These need to be urgently addressed by human rights and health activists, working in tandem with the SW community. Other pieces of legislation, though not specific to sex work, also impact negatively on SWs - such as sodomy laws in Zimbabwe and other countries. These laws create fear among SWs, and instil a deep reluctance to disclose their experiences and actively challenge the shoddy and at times abusive treatment they receive from healthcare workers.

This study highlights yet again the importance of a rights-based approach to health interventions with SWs, which directly addresses the broader historical disempowerment of SWs in the region and frames access to health and dignity as a human-rights issue. The health sector needs to embrace this approach, rather than being content with outdated disease control models, especially those based on a moralistic approach to sex work. SWs and SW-led organisations and collectives need to take centre-stage in this response, as full and active participants, leading outreach programs and taking control of advocacy to reduce stigma and to demand access to health services as any other citizen would enjoy. 


\section{References}

Adu-Oppong, A., R. M. Grimes, M. W. Ross, J. Risser, and G. Kessie. 2007. Social and behavioral determinants of consistent condom use among female commercial sex workers in Ghana. AIDS Education and Prevention 19 (2):160-72.

Ahmad, K. 2001. Call for decriminalisation of prostitution in Asia. Lancet 358 (9282):643.

Akers, N, and C Evans. 2010. St. James Infirmary Occupational Health \& Safety Handbook, San Francisco.

Arnott, J., and A.L. Crago. 2009. Rights Not Rescue: A Report on Female, Male, and Trans Sex Workers' Human Rights in Botswana, Namibia, and South Africa. In Open Society Initiative for Southern Africa, Sexual Health and Rights Project: Open Society Institute. Accessed December 212012. www.opensocietyfoundations.org/sites/default/files/summary 20081114.pdf

Baral, S., C. Beyrer, K. Muessig, T. Poteat, A. L. Wirtz, M. R. Decker, S. G. Sherman, and D. Kerrigan. 2012. Burden of HIV among female sex workers in low-income and middle-income countries: a systematic review and meta-analysis. Lancet infectious diseases 12 (7):538-49.

Church, K., and S. H. Mayhew. 2009. Integration of STI and HIV prevention, care, and treatment into family planning services: a review of the literature. Studies in Family Planning 40 (3):171-86.

Elmore-Meegan, M., R. M. Conroy, and C. B. Agala. 2004. Sex workers in Kenya, numbers of clients and associated risks: an exploratory survey. Reproductive Health Matters 12 (23):50-7.

Godin, G., A. Tinka Bah, A. Sow, I. Minani, D. Morin, and M. Alary. 2008. Correlates of condom use among sex workers and their boyfriends in three West African countries. AIDS and Behavior 12 (3):441-51.

Human Rights Watch. 2010. Comments to Uganda's Parliamentary Committee on HIV/AIDS and Related Matters about the HIV/AIDS Prevention and Control Bill. Accessed December 202012. http://www.hrw.org/sites/default/files/related material/2010 HHR UgandaHIVAnalysis.pdf

Khan, M. R., A. N. Turner, A. Pettifor, K. Van Damme, N. L. Rabenja, N. Ravelomanana, T. Swezey, D. Williams, D. Jamieson, and F. Behets. 2009. Unmet need for contraception among sex workers in Madagascar. Contraception 79 (3):221-7.

Lafort, Y., D. Geelhoed, L. Cumba, C. D. Lazaro, W. Delva, S. Luchters, and M. Temmerman. 2010. Reproductive health services for populations at high risk of HIV: Performance of a night clinic in Tete province, Mozambique. BMC Health Services Research 10:144.

Luchters, S., M. F. Chersich, A. Rinyiru, M. S. Barasa, N. King'ola, K. Mandaliya, W. Bosire, S. Wambugu, P. Mwarogo, and M. Temmerman. 2008. Impact of five years of peer-mediated interventions on sexual behavior and sexually transmitted infections among female sex workers in Mombasa, Kenya. BMC Public Health 8:143.

Nairne D. 2000. "We Want the Power" Findings from focus group discussions in Hillbrow, Johannesburg. Research for sex work 3 (June):3-5.

Open Society Foundations. 2012. 10 reasons to decriminalize sex work. edited by OSI Sexual Health and $\begin{array}{llllll}\text { Rights Project. New } & \text { York. Accessed December } & 2012 .\end{array}$ http://www.opensocietyfoundations.org/sites/default/files/decriminalize-sex-work-20120713.pdf

Prostitution Law Reform Committee, New Zealand Government. 2008. Report of the Prostitution Law Reform Committee on the operation of the Prostitution Reform Act of 2003. Wellington. Accessed December $202012 . \quad$ http://www.justice.govt.nz/policy/commercial-property-andregulatory/prostitution/prostitution-law-review-committee/publications/plrcreport/documents/report.pdf

Pswarayi, G. 2010. Basic Rights Denied to Sex Workers. Global Press Institute. Accessed December 202012. http://www.globalpressinstitute.org/africa/zimbabwe/basic-rights-denied-sex-workers

Rekart, M. L. 2005. Sex-work harm reduction. Lancet 366 (9503):2123-34.

Scorgie, F., M. F. Chersich, I. Ntaganira, A. Gerbase, F. Lule, and Y. R. Lo. 2012. Socio-Demographic Characteristics and Behavioral Risk Factors of Female Sex Workers in Sub-Saharan Africa: A Systematic Review. AIDS and Behavior 16:920-933.

Secretariat: The Global Commission on HIV and the Law. 2012. The Global Commission on HIV and the Law risks, rights and health. edited by UNDP. Geneva: UNDP, HIV/AIDS Group, Bureau for Development 
Policy.

Accessed

December

21

2012.

http://www.hivlawcommission.org/resources/report/FinalReport-Risks,Rights\&Health-EN.pdf

Shaver, F.M. 2005. Sex Work Research: Methodological and Ethical Challenges. Journal of Interpersonal Violence 20 (3):296-319.

Stadler, J., and S. Delany. 2006. The 'healthy brothel': the context of clinical services for sex workers in Hillbrow, South Africa. Culture, Health \& Sexuality 8 (5):451-64.

Steen, R., M. Chersich, and S. J. de Vlas. 2012. Periodic presumptive treatment of curable sexually transmitted infections among sex workers: recent experience with implementation. Current Opinion in Infectious Diseases 25 (1):100-6.

Strauss, A., and J. Corbin. 1998. Basics of qualitative research techniques and procedures for developing grounded theory, 2nd edition. Thousand Oaks: Sage Publications.

Sutherland, E. G., J. Alaii, S. Tsui, S. Luchters, J. Okal, N. King'ola, M. Temmerman, and B. Janowitz. 2011. Contraceptive needs of female sex workers in Kenya - a cross-sectional study. European Journal of Contraception and Reproductive Health Care 16 (3):173-82.

UNAIDS. 2000. Regional UNAIDS workshop on sex work in West and Central Africa.Abidjan, Cote d'Ivoire, 21-24 March 2000.

UNAIDS. 2009. UNAIDS Guidance Note on HIV and Sex Work. Geneva. Accessed December 212012. www.unaids.org/en/media/unaids/contentassets/documents/unaidspublication/2009/JC2306 UN AIDS-guidance-note-HIV-sex-work en.pdf

UNAIDS. 2011. The Report of the UNAIDS Advisory Group on HIV and Sex Work. Geneva. Accessed December 21 2012. http://www.hst.org.za/publications/report-unaids-advisory-group-hiv-and-sexwork

UNAIDS, and Kenya National AIDS Control Council. 2009. Kenya HIV Prevention Response and Modes of $\begin{array}{lllll}\text { Transmission } & \text { Analysis. } & \text { Accessed } & \text { December } & 21\end{array}$ http://siteresources.worldbank.org/INTHIVAIDS/Resources/3757981103037153392/KenyaMOT22March09Final.pdf

Ward, H, and S Day. 2006. What happens to women who sell sex? Report of a unique occupational cohort Sexually Transmitted Infections 82:413-417.

WHO. 2005. Violence against women and HIV/AIDS: critical intersections. Violence against sex workers and HIV prevention. $\quad$ Accessed $\quad$ December $\quad 202012$. http://www.who.int/gender/documents/sexworkers.pdf

WHO. 2012. The strategic use of antiretrovirals to help end the HIV epidemic. Accessed December 202012. http://apps.who.int/iris/bitstream/10665/75184/1/9789241503921 eng.pdf

Wolffers, I., and N. van Beelen. 2003. Public health and the human rights of sex workers. The Lancet 361:1981. 